\title{
The Most Shocking and Inhuman
}

Bich-May Nguyen, MD, MPH

(Fam Med. 2019;51(1):5-7.)

doi: 10.22454/FamMed.2019.175092

$\mathbf{R}$ esearch continues to reveal glaring health disparities American families are facing. Maternal and infant mortality rates are significantly higher among African Americans compared to European Americans. ${ }^{1,2}$ Furthermore, a 2016 report by the New York City Health Department found that women of color are more likely to die than white women. Despite completing college, women of color, especially African-American women, were more likely to die from childbirth than white women who had less than a high school education. ${ }^{3}$ It is striking that educational attainment is not more protective of poor outcomes for mothers of color.

Unfortunately, maternal morbidity and mortality are not the only modern health issues with disproportionate racial impacts. Physicians are less likely to prescribe opioids to black patients in pain. ${ }^{4}$ New HIV infections disproportionately affect African Americans and Latinos. ${ }^{5}$ Suspicions arising from past research abuses may cause people of color to decline some tests or treatments in some situations and request aggressive care in others. Health systems and health care providers must be aware of biases and how they may be treating patients differently.

This dedicated issue of Family Medicine describes what some family medicine departments around the country are doing to tackle this complex subject. In the lead article, Joseph Hobbs, MD, and colleagues at Augusta University review 5 years' worth of family medicine clerkship encounters to determine whether students' race and gender were associated with differences in the types of patients seen by students. ${ }^{6}$ Health care professionals and trainees at the University of California San Francisco, University of Oklahoma-Tulsa, and Tulsa University are learning about unconscious bias, historical events, and social determinants of health. ${ }^{7,8}$

There is no evidence that people of color are inherently genetically frail compared to white people. More likely, racism, not race, explains health disparities. With the recent attention brought to police shootings of African Americans, rise of hate crimes against many minority groups, and demonstrations by white nationalists, the United States must more forcefully confront its history to move forward.

Throughout American medical history, institutional racism has harmed many people of color in the pursuit of health research. Birth control experiments in Puerto Rico and sterilizations in eugenics programs used Latinas. ${ }^{9}$ Researchers sponsored by the US government observed untreated syphilis in poor black men at the Tuskegee Institute in Alabama as well as prisoners and mentally ill people in Guatemala even after treatment became available. ${ }^{10,11}$ These experiments have exploited vulnerable populations without fully informed consent. While these abuses eventually led to stronger protections of potential test subjects, they also understandably have caused minorities to distrust the health care system as well as medical research in general. ${ }^{12}$

Racial disparities within the physician workforce contribute further to this climate of distrust. Medical schools are accepting fewer 
African-American males now compared to the 1970s. ${ }^{13}$ Blacks, Latinos, and Native Americans are not only underrepresented among medical students, but also within medical school faculty. ${ }^{14,15}$ Yet, African-American and Latino patients prefer a physician who resembles them. They report greater satisfaction with their care when their physician is of their own race or ethnicity. ${ }^{16}$ While the United States is becoming more racially and ethnically diverse, the physician workforce is not keeping pace.

Other articles in this special issue address diversity recruitment initiatives and share personal reflections. Brief reports by Maria Wusu, MD, and colleagues at Boston University and Jessica Guh, MD, and colleagues at Swedish Cherry Hill in Seattle outline strategic plans to recruit more diverse faculty and residents. ${ }^{17,18}$ These programs are strengthening their missions to include physicians who reflect the patients for whom they provide care. Often, diversity initiatives can fall under the responsibility of underrepresented minority faculty within their programs. Two such faculty, Veneshia McKinney-Whitson, MD, and Winfred Frazier, MD, MPH, contributed narrative essays on how racism has affected their lives and work. ${ }^{19,20}$

Today, institutional and interpersonal racism continue to create and maintain health disparities by race and ethnicity. The founders of modern family medicine made caring for underserved populations an explicit goal. ${ }^{21} \mathrm{Be}-$ cause of their comprehensive training, family physicians are well prepared to serve a variety of settings, locations, and populations. Physicians have a professional obligation to address and advocate for health equity for their patients and communities. ${ }^{22}$ The last few STFM national conferences have had well-attended sessions on issues of race and ethnicity, indicating a high level of interest within academic family medicine for effective models to teach these issues.

As the United States wrestles with how to respond to rising nationalism and our country's demographics move toward a majority-minority, we must dedicate our work in medicine to countering these forces through our teaching and patient care. Dr Martin Luther King, Jr stated, "Of all the forms of inequality, injustice in health care is the most shocking and inhuman." We must create spaces that are more inclusive and recognize our unconscious biases. We need to commit to fighting injustice in health care and ensuring families can live well to the best of their ability. The real work to make this a reality will have to occur in every single medical practice and training program in the nation. Hopefully, the work detailed by the authors in this special issue will inspire readers to explore ways to better serve their own communities.

CORRESPONDENCE: Address correspondence to BichMay Nguyen, MD, Physicians at Sugar Creek, 14023 Southwest Fwy, Sugar Land, TX 77478. 281-0325-4100. Bich-May.Nguyen@memorialhermann.org.

\section{References}

1. Ely DM, Driscoll AK, Mathews TJ. Infant Mortality by Age at Death in the United States, 2016. NCHS Data Brief, no 326. Hyattsville, MD: National Center for Health Statistics; 2018. https://www.cdc.gov/nchs/products/databriefs/db326. htm. Accessed November 24, 2018.

2. Moaddab A, Dildy GA, Brown HL, et al. Health Care Disparity and State-Specific Pregnancy-Related Mortality in the United States, 2005-2014. Obstet Gynecol. 2016;128(4):869-875.

3. New York City Department of Health and Mental Hygiene. Severe Maternal Morbidity in New York City, 2008-2012. New York, NY. 2016. https://www1.nyc.gov/assets/doh/ downloads/pdf/data/maternal-morbidity-report-08-12.pdf Accessed November 24, 2018.

4. Singhal A, Tien YY, Hsia RY. Racial-Ethnic Disparities in Opioid Prescriptions at Emergency Department Visits for Conditions Commonly Associated with Prescription Drug Abuse. PLoS One. 2016;11(8):e0159224.

5. Centers for Disease Control and Prevention. HIV Surveillance Report, 2017; vol. 29. http://www.cdc.gov/hiv/library/ reports/hiv-surveillance.html. Accessed November 24, 2018.

6. Hobbs J, Kriegel DL, Saucier A, Hodo DM, Looney SW. Student race and gender and patient encounters in a family medicine clerkship. Fam Med. 2019;51(1):14-21.

7. Wu D, Saint-Hilaire L, Pineda A, Hessler D, Saba G, Salazar R, Olayiwola JN. The efficacy of an antioppression curriculum for health professionals. Fam Med. 2019;51(1):2230 .

8. Dennis SN, Gold RS, Wen FK. Learner reactions to activities exploring racism as a social determinant of health. Fam Med. 2019;51(1):41-47.

9. Mass B. Puerto Rico: A case study of population control. Lat Am Perspect. 1977;4(4):66-82.

10. Brandt AM. Racism and Research: The case of the Tuskegee Syphilis Study. Hastings Cent Rep. 1978;8(6):21-29.

11. US Department of Health and Human Services. Fact Sheet on the 1946-1948 U.S. Public Health Service Sexually Transmitted Diseases (STD) Inoculation Study. http://www. hhs.gov/1946inoculationstudy/factsheet.html. Accessed September 12, 2017.

12. Freimuth VS, Quinn SC, Thomas SB, Cole G, Zook E, Duncan T. African Americans' Views on Research and the Tuskegee Syphilis Study. Soc Sci Med. 2001;52(5):797-808. 
13. Association of American Medical Colleges. Altering the Course: Black Males in Medicine. Washington, DC; 2015 https://store.aamc.org/altering-the-course-black-males-inmedicine.html. Accessed November 24, 2018.

14. Rodríguez JE, Campbell KM, Adelson WJ. Poor representation of blacks, Latinos, and Native Americans in medicine. Fam Med. 2015;47(4):259-263.

15. Rodríguez JE, Campbell KM, Fogarty JP, Williams RL. Underrepresented minority faculty in academic medicine: a systematic review of URM faculty development. Fam Med. 2014;46(2):100-104.

16. Chen FM, Fryer GE, Phillips R, Wilson E, Pathman DE. Patients' beliefs about racism, preferences for physician race, and satisfaction with care. Ann Fam Med. 2005;3(2):138-143.

17. Wusu MH, Tepperberg S, Weinberg JM, Saper RB. Matching our mission: a strategic plan to create a diverse family medicine residency. Fam Med. 2019;51(1):31-36.
18. Guh J, Harris CR, Martinez P, Chen FM, Gianutsos LP. Antiracism in residency: a multimethod intervention to increase racial diversity in a community-based residency program. Fam Med. 2019;51(1):37-40.

19. McKinney-Whitson V. I guess the MD on my white coat is invisible today. Fam Med. 2019;51(1):57

20. Frazier W. I'm not here to judge. Fam Med. 2019;51(1):5556 .

21. Stephens GG. Family medicine as counterculture. Fam Med. 1989;21(2):103-109.

22. American Medical Association. Declaration of Professional Responsibility. 2001. https://www.cms.org/uploads/ Declaration-of-Professional-Responsibility.pdf. Accessed November 24, 2018. 